\title{
Descrição anátomo-radiográfica do esqueleto apendicular da paca (Agouti paca)
}

\author{
Anatomoradiographic description of the apendicular skeleton of paca (Agouti paca) \\ Fabrício Singaretti de Oliveira ${ }^{1}$, Júlio Carlos Canola², Márcia Rita \\ Fernandes Machado² \& Mauro Henrique Bueno de Camargo²
}

\begin{abstract}
RESUMO
O esqueleto apendicular é a parte do esqueleto que compreende os ossos dos membros e o conhecimento anátomoradiográfico desses ossos torna-se muito importante para clínico-cirurgicamente. Esta pesquisa foi desenvolvida para melhor se conhecer alguns aspectos anátomo-radiográficos do esqueleto apendicular do segundo maior roedor silvestre brasileiro, a paca. Foram utilizados seis animais de até um ano de idade e seis com mais de um ano, pertencentes ao Setor de Animais Silvestres da Faculdade de Ciências Agrárias e Veterinárias, Campus de Jaboticabal, SP. Os animais foram anestesiados e radiografados em decúbito lateral e ventral para descrição do esqueleto apendicular. Para a descrição anatômica, os ossos de quatro animais foram utilizados, além da dissecção de dois animais. A cintura escapular da paca consiste de duas escápulas e duas longas clavículas. O úmero possui tubérculo maior evidente e fossa radial e do olécrano comunicantes. As tuberosidades do rádio são pouco nítidas e o mesmo não é fundido à ulna. Os carpos intermediorradial, ulnar, acessório e falciforme formam a fileira proximal e os carpos I e II (fundidos), III e IV a distal. Há cinco dedos no membro torácico e sesamóides em todos metacarpos, menos no I. A pelve é estreita, alongada e o acetábulo arredondado e profundo. O trocânter maior femoral é bem desenvolvido, diferentemente dos demais trocânteres. A tíbia e fíbula são parcialmente fundidas nas extremidades. No membro pélvico há cinco dedos e os metatarsos II, III, IV e V possuem sesamóides. No tarso, a fileira proximal é composta pelo talo, calcâneo, osso társico tibial medial e central; na fileira distal há o tarsometatarso I, e o II, III e IV ossos do tarso.
\end{abstract}

Descritores: anatomia, radiografia, esqueleto apendicular, paca, Agouti paca.

\section{ABSTRACT}

The apendicular skeleton is formed by the bones of the members and the anatomoradiographic knowledge of those is extremely important clinic and surgically. This research was developed with the purpose of better know some anatomoradiographic aspects of the apendicular skeleton of the second biggest wild brazilian rodent, the paca. Six animals up to one year old and six older than that, belonging to the Sector of Wild Animals of the Faculty of Veterinary and Agrarian Sciences, Campus of Jaboticabal, SP, were used. Animals were anesthetized and x-rayed in lateral and ventral recumbency for apendicular skeleton description. As for the anatomical report, bones from four animals were utilized, besides the dissection of two thawed animals. The pectoral girdle consists of two scapulae and two clavicles. The humerus possesses evident greater tubercle and the radial and olecranus graves are perforated. The radio tuberosities are little evident and it is not fused to the ulna. The intermedioradial, ulnar, accessory and falciform form the proximal and the I and II (fusioned), III e IV carpal bones the distal row of carpus. There are five fingers in the forelimb and sesamoids in all metacarpal bones, but in the I. The pelvis is narrow, lengthened and with a rounded and deep acetabulum. The femoral greater trochanter is distinct, unlike the other trochanters. The tibia and fibula are partially fused in the tips. There are five fingers in the hindlimb and the II, III, IV and V metatarsal bones possess sesamoids. Calcaneus, talus, medial tibial tarsal and central form the proximal row and the tarsometatarsal bone I, the II, III and IV tarsal the distal row of tarsus.

Key words: anatomy, radiograph, apendicular skeleton, paca, Agouti paca. 


\section{INTRODUÇÃO}

$\mathrm{O}$ esqueleto apendicular é a parte do esqueleto que compreende os ossos dos membros [2] e é um dos constituintes do aparelho locomotor muito bem descrito em animais domésticos e de laboratório. Há evidentes diferenças entre os membros pélvicos e torácicos e estas estão relacionadas à flexibilidade e apoio do corpo [3].

Em espécies selvagens, informações anatômicas ou radiográficas sobre o esqueleto apendicular são escassas, principalmente em relação aos roedores, como a paca (Agouti paca), tornando, dessa forma, bastante difícil a descrição de afecções e interpretação de exames que envolvam esses ossos.

Em pacas, os poucos relatos sobre o sistema locomotor descrevem que a forma externa do corpo desses animais é modificada para corrida e os membros, especialmente os pélvicos, são longos, possuindo dedos laterais reduzidos. O primeiro dedo é vestigial e o membro torácico desses animais apresenta quatro dígitos funcionais, e o pélvico, cinco. Em outro roedor, a cutia (Dasyprocta sp.), há quatro dígitos torácicos e três dígitos pélvicos [7].

O objetivo desse trabalho foi descrever, anátomoradiograficamente, o esqueleto axial de um dos maiores roedores brasileiros, a paca, a fim de comparar com os dados existentes na literatura.

\section{MATERIAIS E MÉTODOS}

Foram utilizados seis animais de até um ano de idade (três machos e três fêmeas) e seis animais com mais de um ano (três machos e três fêmeas), pertencentes ao Setor de Animais Silvestres do Departamento de Zootecnia da Faculdade de Ciências Agrárias e Veterinárias, Campus de Jaboticabal, SP. Os animais foram anestesiados e radiografados em decúbito lateral e ventral para descrição do esqueleto apendicular. Para a descrição anatômica, os ossos do esqueleto apendicular de quatro animais (um macho e uma fêmea adultos, um macho e uma fêmea filhotes) foram utilizados, além da dissecção de dois animais (um macho adulto e uma fêmea filhote), que vieram a óbito após ferimentos graves por brigas.

\section{RESULTADOS}

A cintura escapular da paca consiste de duas escápulas e duas clavículas. Cada escápula possui uma espinha que termina no acrômio, e apresenta um grande processo hamato que se projeta ventralmente.
As clavículas são ossos longos, estreitos e levemente curvos, localizadas entre o processo hamato da escápula e o manúbrio do esterno (Figura 1).

$\mathrm{O}$ úmero possui longo eixo, cabeça arredondada, tubérculo maior evidente, tubérculo menor e tuberosidade deltóide pouco pronunciados, e fossa radial e fossa do olécrano comunicantes. O rádio é curvo sobre a ulna, principalmente no terço distal, e as tuberosidades radial, lateral e medial são pouco nítidas; não são fundidos e os comprimentos de seus corpos se equivalem.

Há cinco dedos no membro torácico, mas somente os dedos II a $\mathrm{V}$ possuem três falanges (proximal, média e distal); o dedo I possui falanges proximal e distal e há sesamóides em todos os metacarpos, menos no I. A fileira proximal de carpos é formada pelos carpos intermediorradial, ulnar, acessório e falciforme (este último, ventralmente ao acessório) e a fileira distal pelos carpos I e II (fundidos), III e IV (Figura 2).

A pelve das pacas é estreita, alongada e formada por um par de ílios, ísquios e púbis. Os ílios são grandes e praticamente paralelos, assim como os ísquios. Os púbis se encontram na sínfise púbica e entre cada um deles e no ísquio há um grande forame obturador. $\mathrm{O}$ acetábulo, formado pelos três ossos da pelve, é arredondado e profundo, o que confere boa estabilidade coxo-femoral.

No membro pélvico há cinco dedos, mas o I dedo é reduzido, possuindo apenas falanges proximal e distal; os demais possuem três falanges. Os metatarsos II, III, IV e V possuem sesamóides. No tarso, a fileira proximal é composta pelo talo, calcâneo, osso társico tibial medial e central do tarso; na fileira distal há o tarsometatarso I, e o II, III e IV ossos do tarso (Figura 3).

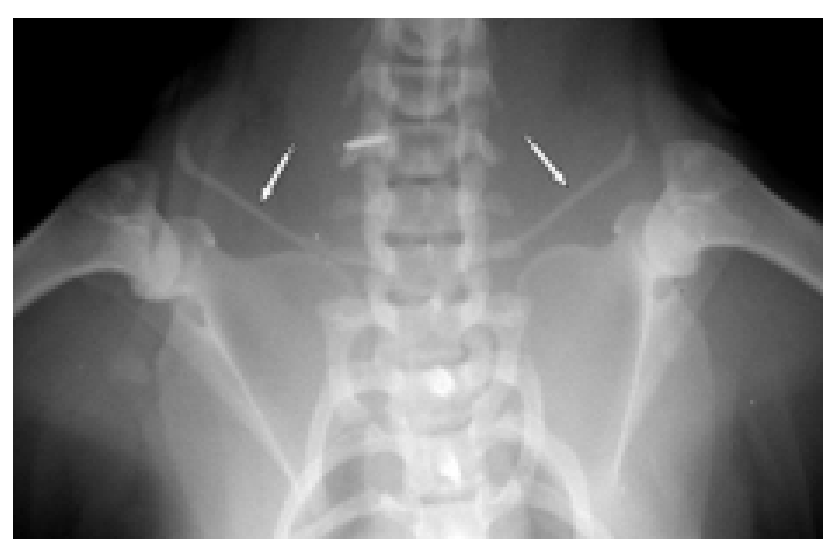

Figura 1. Imagem radiográfica ventrodorsal da região cérvicotorácica de paca. Notar a presença das longas e estreitas clavículas (setas). 

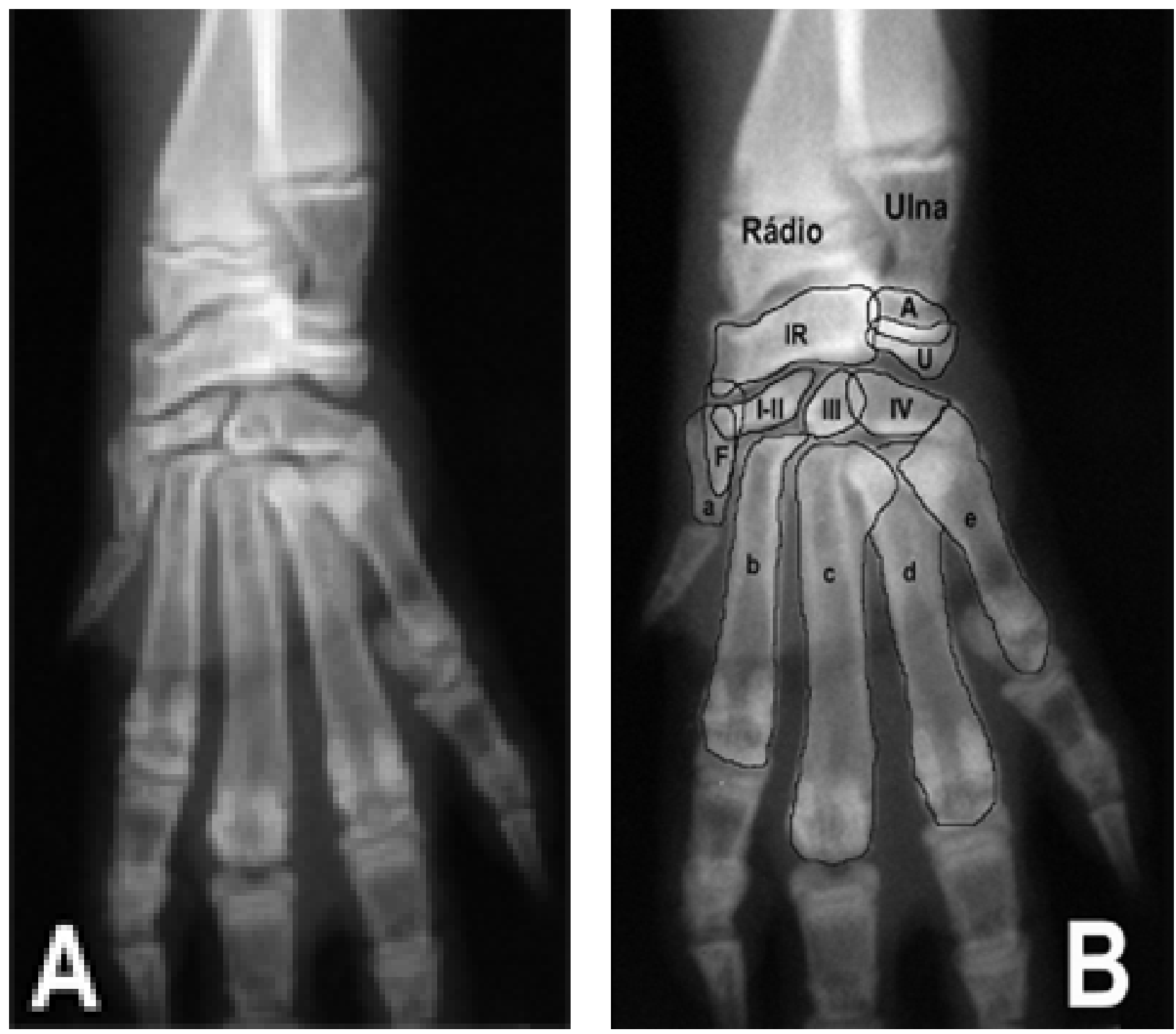

Figura 2. A - Imagem radiográfica dorsopalmar do carpo e metacarpo de paca. B - a mesma imagem de "A" com delimitação dos ossos. IR: carpo intermediorradial; A: acessório do carpo; U: ulnar do carpo; F: carpo falciforme; I-II: osso cárpico I e II; III: osso cárpico III; IV: osso cárpico IV; a-e: primeiro ao quinto metacarpo.

O fêmur da paca possui longo eixo, cabeça arredondada e cólo evidente; o trocânter maior é bem desenvolvido, diferentemente do trocânter menor e do terceiro trocânter. A tíbia e a fíbula se equivalem em comprimento e são parcialmente fundidas por uma fibrocartilagem em suas extremidades. A borda cranial da tíbia se pronuncia até o terço médio da diáfise e é praticamente paralela ao maior eixo ósseo.

\section{DISCUSSÃO}

Cada escápula possui uma espinha que termina no acrômio, e apresenta um grande processo hamato que se projeta ventralmente, diferentemente do rato de laboratório (Rattus norvegicus), que possui um pequeno processo metacrômio na borda ventral escapular [1]. Radiograficamente, as clavículas são ossos longos, estreitos e levemente curvos, como as do rato de laboratório, camundongo (Mus musculus), hamster dourado (Mesocricetus auratus) e chinchila (Chinchilla lanigera) [6] e as do rato-toupeira pelado (Heterocephalus glaber) [4], e diferentemente das do cobaio (Cavia porcellus), que são pequenas e menos evidentes [6].

$\mathrm{O}$ úmero possui longo eixo e cabeça arredondada e o rádio é curvo sobre a ulna e estes não são fundidos, como no rato de laboratório [1], ou fundidos apenas no antímero direito, como no rato-toupeira pelado. $\mathrm{O}$ rádio e a ulna da paca são similares aos do antímero esquerdo do rato-toupeira pelado, ou seja, 

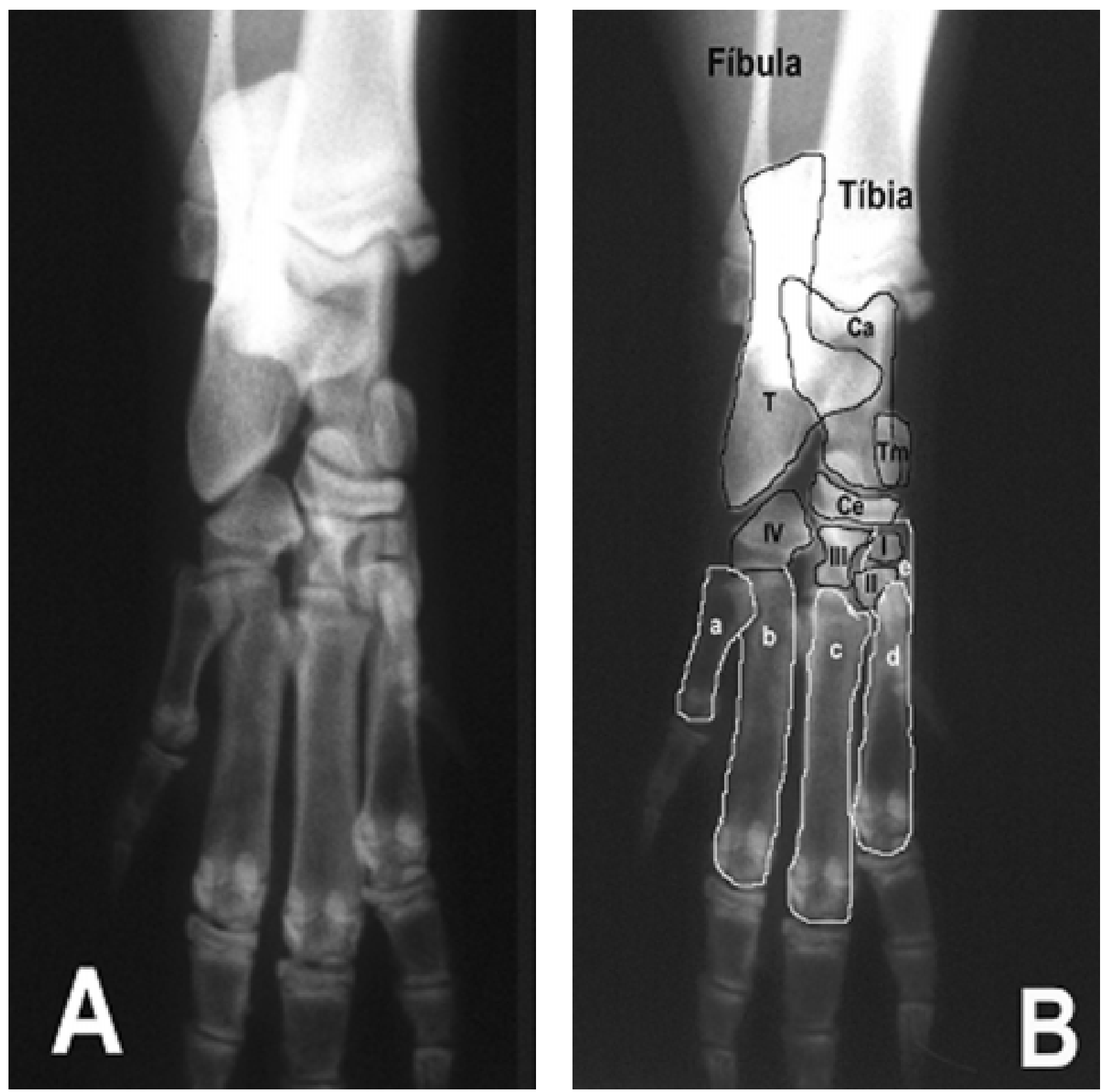

Figura 3. A - Imagem radiográfica dorsoplantar do tarso e metatarso de paca. B - a mesma imagem de "A", com delimitação dos ossos. T: talo; Ca: Calcâneo; Tm: tarso tibial medial; Ce: central; I: tarsometatarso I; II a IV: segundo a quarto ossos do tarso; "a" a "e": primeiro a quinto ossos do metacarpo.

são distintos [4]. Diferentemente do rato-toupeira pelado [4], o úmero não apresenta tuberosidades bem desenvolvidas, com exceção do tubérculo maior.

Nos carpos, a fileira proximal (intermediorradial, ulnar, acessório e falciforme) é formada por quatro ossos e a distal (carpos I e II fundidos, III e IV) por três, diferentemente do cobaio, que possui quatro ossos em ambas fileiras [6], do rato de laboratório, o qual possui dois ossos na fileira proximal e cinco na distal [1], e do chinchila, que apresenta três (não há o carpo falciforme) e quatro ossos, respectivamente [6].
Há cinco dedos no membro torácico, como as descrições prévias feitas para a mesma espécie [7], e diferentemente dos relatos do mesmo autor para a cutia, a qual apresenta apenas quatro dígitos torácicos, assim como o cobaio [6]. Há 14 falanges e o primeiro metacarpo é muito mais curto que os demais, como no rato de laboratório [1] e no rato-toupeira pelado [4].

Diferentemente do descrito para o rato de laboratório [1], no qual há a descrição do osso cotilóide na pelve, nas pacas esta é formada apenas por um par de ílio, ísquio e púbis. 
O fêmur da paca possui longo eixo e cabeça arredondada, como no rato de laboratório [1]. Apresenta três trocânteres, como no rato-toupeira pelado [5], embora o trocânter menor e o terceiro trocânter sejam bem reduzidos. A tíbia e a fíbula são parcialmente fundidas por uma fibrocartilagem em suas extremidades, como as do rato de laboratório [1]. Apresenta oito ossos társicos, como o rato-toupeira pelado [5] e o chinchila [6] e cinco metatarsos com 14 falanges, como o rato-toupeira pelado [5] e o rato de laboratório [1]. No tarso, a fileira proximal é composta pelo talo, calcâneo, osso társico tibial medial e central do tarso, como o cobaio, e na fileira distal há o tarsometatarso I, e o II, III e IV ossos do tarso, diferentemente do cobaio, o qual não apresenta apenas o IV osso do tarso [6].
As pacas possuem cinco dígitos pélvicos, diferentemente da cutia, que possui três dígitos [7], e do cobaio, que possui quatro [6]. Entretanto, apresentam o mesmo número de dígitos pélvicos que o rato de laboratório [1], o rato-toupeira pelado [5] e os chinchilas [6].

\section{CONCLUSÕES}

As pacas são animais compactos, de pequeno comprimento longitudinal e com características ósseas do esqueleto apendicular que são diferentes daquelas dos roedores de laboratório. O melhor conhecimento dessas características anátomo-radiográficas poderá contribuir na descrição de afecções e interpretação de exames que envolvam esses ossos, assim como na realização de futuros estudos nessa espécie.

\section{REFERÊNCIAS}

1 Calam A. \& Baker N. 2001. Disponível em <http://137.222.110.150/calnet/ratskele/_ratskele.htm>. Acessado em 05 jan 2006.

2 Getty R. 1986. Osteologia geral. In: Sisson S. \& Grossman J.D. (Eds). Anatomia dos animais domésticos. 5.ed. Rio de Janeiro: Guanabara Koogan. pp.19-23.

3 Heithaus P.A. 2005. Disponível em <http://biology.kenyon.edu/courses/biol09/Rat/welcome.htm>. Acessado em 06 jan 2006.

4 Ozkan Z.E. 2002. Macro-anatomical investigations on the forelimb skeleton of mole-rat (Spalax leucodon Nordmann). Veterinarski Arhiv. 72: 91-99.

5 Ozkan Z.E. 2002. Macro-anatomical investigations on the hind limb skeleton of mole-rat (Spalax leucodon Nordmann). Veterinarski Arhiv. 72: 159-166.

6 Silverman S. \& Tell L.A. 2005. Radiology of rodents, rabbits and ferrets: an atlas of normal anatomy and positioning. St. Louis: Elsevier. 299p.

7 Woods C.A. 1984. Hystricognath rodents. In: Anderson S. \& Jones JR. J. K. (Eds). Orders and families of recent mammals of the world. New York: John Wiley \& Sons. pp.389-446. 